\title{
Commentary: What is the best surgical technique to repair partial anomalous pulmonary venous return into the superior vena cava? We still do not know
}

\author{
David Kalfa, MD, PhD
}

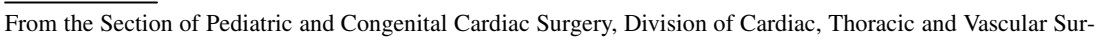
gery, New York Presbyterian-Morgan Stanley Children's Hospital, Columbia University Medical Center, New York, NY.

Disclosures: Author has nothing to disclose with regard to commercial support.

Received for publication Jan 28, 2019; accepted for publication Jan 28, 2019; available ahead of print Feb 22, 2019.

Address for reprints: David Kalfa, MD, PhD, Pediatric Cardiac Surgery, New York Presbyterian-Morgan Stanley Children's Hospital, Columbia University Medical Center, 3959 Broadway, New York, NY 10032 (E-mail: dk2757@cumc.columbia.edu).

J Thorac Cardiovasc Surg 2019;157:1980-1

0022-5223/\$36.00

Copyright $(5) 2019$ by The American Association for Thoracic Surgery

https://doi.org/10.1016/j.jtcvs.2019.01.098

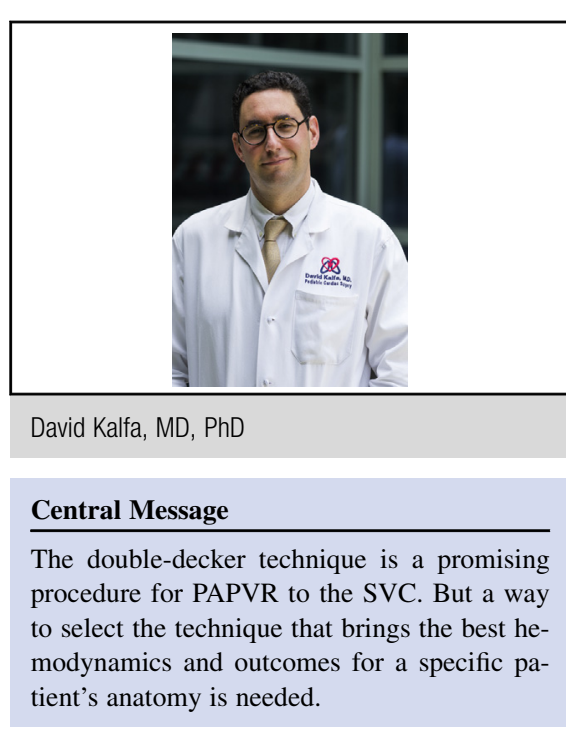

See Article page 1970.
In this issue of the Journal, Hongu and colleagues ${ }^{1}$ from Kyoto describe an innovative technique for partial anomalous pulmonary venous return to the superior vena cava (SVC) that is based on a double-barreled arrangement of systemic and pulmonary venous channels. They demonstrate promising results, with no supraventricular arrhythmias and no systemic or pulmonary venous obstruction in a series of 21 patients operated on during a span of 20 years with a median follow-up period of 11.0 years. Advantages of this technique are numerous: (1) the limited atriotomy is away from the sinus node, sinus nodal artery, and crista terminalis; (2) there is no incision across the cavoatrial junction; (3) an anastomosis of the entire circumference of the venous channels is avoided; and (4) both channels keep a growth potential. Their use of a 4-dimensional flow magnetic resonance imaging to calculate blood flow volumes, wall shear stress, and flow patterns is also of interest.

The outcomes of this technique are promising. Nevertheless, the small series of patients ( 21 during 20 years of practice) does not allow Hongu and colleagues ${ }^{1}$ to state in a definitive way that postoperative complications are entirely avoided. A larger and multicentric series of patients is needed to formulate such a statement. Second, the anastomosis of the systemic channel beyond the sinoatrial nodal artery decreases the risk of injury to the sinus node. Things are not so simple in real life, however, because the exact location of the sinus node and this artery can vary, and the tension of the anastomosis of the systemic channel can compress the sinus node or the artery. Third, when the pulmonary veins enter high in the SVC or there is a lack of atrial tissue to work with, this technique brings a risk of kinking of the SVC-right atrial junction if too much tension is applied to the advancing flap of right atrial appendage to reach the SVC. Hongu and colleagues ${ }^{1}$ state that supplemental material is necessary only in exceptional cases, but this still represents 6 of 21 patients in the series. Fourth, the growth potential of the channels is not an appanage of the double-decker technique, and, although a flap of autologous pericardium may have growth potential, ${ }^{2,3}$ it is still controversial whether a patch does.

Despite these limits, the group from Kyoto ${ }^{1}$ reports remarkable outcomes of an astute and ingenious new surgical technique to repair partial anomalous pulmonary venous return to the SVC, and they are to be congratulated for this significant contribution. We have now an additional technique to our armamentarium to treat this condition. The Warden, patch (single or double), and double-decker techniques are complementary options, with choice depending on the location of the sinus node artery, right atrial dilation, location of the pulmonary veins, SVC size, and so on. The next step that our community should focus on now is collaboration with engineers to apply the progress of computational modeling to this clinical question and set up a patient-based computational model to predict which technique would lead to less turbulent flow, and thus to the best long-term outcomes, for a specific patient with a specific anatomy, offering a personalized, tailored, and optimized decision for each patient. 


\section{References}

1. Hongu H, Yamagishi M, Maeda Y, Itatani K, Asada S, Fujita S, et al. Double-decker repair of partial anomalous pulmonary venous return into the superior vena cava. J Thorac Cardiovasc Surg. 2019;157:1970-7.

2. Adachi I, Yagihara T, Kagisaki K, Hagino I, Ishizaka T, Koh M, et al. Fontan operation with a viable and growing conduit using pedicled autologous pericardial roll: serial changes in conduit geometry. J Thorac Cardiovasc Surg. 2005;130: 1517-22.

3. Guyton RA, Dorsey LM, Silberman MS, Hawkins HK, Williams WH, Hatcher JC Jr. The broadly based pericardial flap. A tissue for atrial wall replacement that grows. J Thorac Cardiovasc Surg. 1984;87: 619-25. 